\title{
Are Cows Comfortable in Modern Dairy Facilities?'
}

\author{
Izabella Toledo
}

During the past decades, US dairies have become larger and housing types have changed from traditional stanchion facilities to free stalls, compost barns, and dry lots. Largescale dairies have become common because of consolidation of the industry. The main challenge of modern large dairy operations is to achieve high milk yield per cow without sacrificing health and welfare. Properly designed and managed facilities allow calves, heifers, and cows to be comfortable and successfully grow, mature, maintain health, and reach peak performance.

Dairy industry professionals have been working for many years to understand cow needs and improve dairy cattle comfort. It is crucial to provide calves, heifers, and mature cows with basic shelter needs, which include good access to feed and water, dry, clean, and comfortable resting area, sufficient space to express natural behavior, appropriate ventilation, heat abatement, good air quality, and minimal animal stress. In addition, facilities should allow farm staff to easily and safely handle cows, diagnose and treat injuries and diseases, feed, and provide cows with a clean environment.

\section{Facilities and Cow Comfort}

Cow comfort is the result of minimizing cow stress to maximize milk production and animal well-being. The environment in which dairy cows spend the majority of their time has considerable impact on productivity, health, milk quality, reproduction, animal well-being, and farm profitability. An effective way to determine if cows are comfortable is by analyzing their behavior and performance. In addition, good farm record keeping allows us to effectively improve cow comfort by assessing group and individual milk production, feed intake, health, and reproductive performance in response to improvements in facilities.

Cows need to accomplish certain natural behavioral activities on a daily basis. It is important to understand that disruption of these daily activities by inappropriate farm management practices results in decreased dairy cattle performance and economic losses. The table below shows a typical daily time budget of dairy cattle in a free-stall environment.

Table 1.

\begin{tabular}{|l|c|}
\hline \multicolumn{1}{|c|}{ Activity } & $\begin{array}{c}\text { Time Devoted to } \\
\text { Activity (per day) }\end{array}$ \\
\hline Eating & 3 to $5 \mathrm{~h}(9$ to 14 meals/d) \\
\hline Lying/resting & 12 to $14 \mathrm{~h}$ \\
\hline Social interactions & 2 to $3 \mathrm{~h}$ \\
\hline Ruminating & 7 to $10 \mathrm{~h}$ \\
\hline Drinking & $0.5 \mathrm{~h}$ \\
\hline Outside pen (milking, travel time) & 2.5 to $3.5 \mathrm{~h}$ \\
\hline Adapted from Grant and Albright (2000). \\
\hline
\end{tabular}

The typical daily time budget of a dairy cow and the physical features of a dairy facility will determine how the cows will behave and function within that housing. In order to maintain optimal dairy cow performance, it is always important to pay close attention to factors that may decrease or limit their ability to express natural behaviors. These factors include but are not limited to resting area

1. This document is AN349, one of a series of the Department of Animal Sciences, UF/IFAS Extension. Original publication date December 2018. Visit the EDIS website at https://edis.ifas.ufl.edu for the currently supported version of this publication.

2. Izabella Toledo, PhD, dairy Extension specialist; UF/IFAS Extension Lafayette County, Mayo, FL 32066.

The Institute of Food and Agricultural Sciences (IFAS) is an Equal Opportunity Institution authorized to provide research, educational information and other services only to individuals and institutions that function with non-discrimination with respect to race, creed, color, religion, age, disability, sex, sexual orientation, marital status, national origin, political opinions or affiliations. For more information on obtaining other UF/IFAS Extension publications, contact your county's UF/IFAS Extension office. 
(stall design, bedding, and footing), resting behavior, time spent away from pen (i.e., for milking and other management procedures), feed and water access and availability, stocking density, and environmental factors such as heat stress.

\section{Resting Area, Resting Behavior, and Time Spent Away from Pen}

When analyzing the daily time budget of a dairy cow, we clearly observe that cows naturally have a strong need to rest. Lying behavior has a high priority for dairy cows, and lying deprivation results in decreased milk production, well-being, and profitability. Factors that may influence the amount of time a cow spends lying include facility design and installation, management practices, environmental factors, and physiological status of the cow.

A dairy cow spends $70 \%$ of a day eating and resting. Many studies have shown that cows will sacrifice eating time to compensate for lost resting time. They usually increase feeding rate to make up for a decrease in eating time, as lying time takes priority over eating (Metz 1985; Hopster et al. 2002; Munksgaard et al. 2005; Cooper, Arney, and Phillips 2007). Benefits of resting include greater milk synthesis due to increased blood flow through the udder. A standing cow circulates 60 gallons of blood per hour through her udder compared with 90 gallons per hour in a recumbent cow. Grant (2004) reported an increase of 2.0 to 3.5 more pounds of milk per cow daily for each extra hour of resting time. In addition, increasing resting behavior results in greater blood flow to the uterus during late gestation, greater feed intake and rumination, and a decrease in lameness.

When designing facilities, it is important to ensure that cows have the opportunity to meet their lying time requirements by providing them with a dry and clean resting area. Facilities' design should also minimize the chance of injury when cows are being moved in and out. In free-stall facilities, variations in stall design and management are associated with changes in lying time. Bedding type, amount, and moisture content, as well as stall size, neck rail placement, and stocking density significantly influence lying time (Reich et al. 2010). Additionally, regular removal of manure and urine from cow alleys is critical for maintenance of optimal resting surface conditions. Good ventilation and air quality are also essential to keep floor and rest areas dry. To allow optimal cow comfort in freestall facilities, it is important to consider that differences in sizes of cows within a herd should result in varying stall sizes. It is practical to select free stall dimensions for the largest cows; however, first lactation cows should be kept in a separate pen with smaller free stalls whenever possible. Table 2 shows dimension recommendations for free stalls by cow size.

Many studies have compared the effects of different types of bedding on cow health and productivity. Calamari, Calegari, and Stefanini (2009) used free-stall facilities to compare different bedding materials, which included sand, straw, rubber mats, and mattresses. Milk yield was maintained in cows resting on a sand bed during the eight weeks of the study. Cows resting in the other three alternative beds had decreased milk yield throughout the study. During the final three weeks of the study, cows resting in sand beds had an advantage of 11.6 extra pounds of milk per day compared to cows resting on the other bedding. Researchers concluded that the results were due to a loss in resting time when materials other than sand were used for bedding. Sand is an inorganic bed material that, when properly managed, does not support the growth of bacteria. It is associated with a reduced incidence of clinical mastitis caused by environmental organisms such as Escherichia coli and environmental streptococci.

Although sand has been considered by many as the best bedding material for free-stall housing, alternative bedding materials are also well-accepted and comfortable. Wagner-Storch, Palmer, and Kammel (2003) conducted a comparative study by using foam mattress, rubber crumb mattress, waterbed, solid rubber mat, and concrete with sawdust as bedding materials. The study was performed in understocked conditions, so cows could choose and have access to all of the available bedding materials. Sand was the most preferred, and it provided cows with the greatest comfort level; however, foam mattresses closely followed sand. Other materials such as rubber crumb mattresses and waterbeds were also well-accepted, which led to the conclusion that when sand is not an option, other materials may be good alternatives for bedding in free stall facilities. Many research groups have measured the lying response of cows to various amounts of bedding. Tucker et al. (2009) summarized the results of different studies and concluded that cows prefer softer, more compressible lying surfaces, which are associated with increases in resting time.

When choosing a floor surface for any type of dairy facility, it is important to consider the facility's layout and traffic flow. Proper footing is crucial for cow comfort, as it minimizes claw lesions and provides security for cows to express normal behaviors and walk across floor surfaces with greater ease. If cows have difficulty walking on a specific 
type of flooring, an increase in lying time and decrease in water and feed intake may be observed. Floor surfaces should be kept relatively dry to minimize bacterial growth and occurrence of claw and leg diseases. Poor flooring surfaces in the barn and holding pen result in increased incidence of lameness, which impacts production and causes serious economic losses in dairy operations. Concrete floors are commonly used in dairy facilities because they are durable and easy to clean. All concrete floors should be grooved to prevent slippage. However, there is a fine line between a concrete floor surface that is too rough, causes injury due to abrasion, and results in excessive wear of hooves and one that is too smooth and does not offer sufficient traction. Research has shown that rough finished floors speed foot wear by up to $20 \%$ and increase culling of cows during the first three weeks of a new barn occupancy due to lameness (Bray 1998). Alternatively, the addition of anti-slip aggregates helps minimize injuries due to slippage and can also extend the life of concrete floors. While concrete floors are durable and easy to clean, they can cause stress to the legs and hooves if stood on for long periods of time. Free-stall barns offer many flooring alternatives such as belting, rolled rubber, rubber mats, and pour-in-place rubber flooring, which may be considered in order to improve cow comfort and reduce stress to cows' hooves and legs.

Time spent away from the stall for milking or other management procedures directly impacts resting time. Matzke (2003) showed that cows that spent more than 3.5 hours per day away from stalls had a reduction in resting time, which resulted in a decrease in 5 to 8 pounds of milk per day. In addition, lameness prevalence in productive herds has been associated with increased times outside the pen (Espejo and Endres, 2007). Gomez and Cook (2010) showed an interaction between time spent outside the pen (milking and walking) and lameness. For cows with a lameness score of 3 (on a scale of 1 to 3 ) to meet their requirement of 11 to 12 hours a day of resting time, they could only be outside of the pen for 0.5 to 1.5 hours per day. In comparison, healthy cows with a lameness score of 1 were able to stay outside the pen for 2 to 4 hours per day and still meet their daily resting requirement. At some point, it is impossible to meet the required daily time budget with lame cows.

Cows kept in a well-designed and maintained facility rest comfortably. Overton et al. (2002) documented that cows have a pattern of temporal cyclicity in their lying behavior. The highest percentage of cows lying (80 to 91\%) is observed during the early morning and late evening hours, while the lowest percentage (59.6\%) of cows lying is observed during the first hour after milking.

\section{Feed and Water Access and Availability}

Feed and water access and availability are critical for dairy production and performance. One of the keys to success in dairy production is to design and manage facilities that maximize dry matter intake and water consumption. Several management, environmental, and cow factors influence feed and water intake. Management factors include stocking density, feeding consistency, feed quality, access to feed and water, and an unlimited supply of clean, fresh water. Environmental factors include climatic conditions (such as temperature and humidity), bunk space, and cow comfort. Cow factors include stage of lactation, lactation number, milk yield, body weight, body condition score, and cow grouping. By understanding how these factors control intake, producers and dairy industry professionals can improve nutritional management protocols.

The modern dairy cow has been genetically selected to have the capacity to produce large amounts of milk. It is the producers' responsibility to provide them with the best possible nutrition, so the cows can reach their full potential. Dairy cows have very high nutrient requirements and must eat a well-balanced diet with enough energy, protein, fiber, water, minerals, and vitamins to optimize maintenance, growth, and production during different ages and physiological stages.

Water is the most important nutrient for dairy cattle and the main component of milk. Each cow consumes 30 to 50 gallons of water (115 to $190 \mathrm{~L}$ ) a day, and water accounts for $87 \%$ of the milk she produces. Water requirements of dairy cows are variable and related to milk production, dry matter intake, diet composition, air temperature, humidity, and water quality. It has been estimated that a lactating cow needs to consume 0.5 gallons $(1.9 \mathrm{~L})$ of water for every pound $(0.45 \mathrm{~kg}$ ) of milk produced (Beede 2005$)$. In general, dairy cows spend 4 to 5 hours a day eating, and only 20 to 30 minutes a day drinking water; therefore, water tanks need to be easily accessible to optimize water consumption. Tanks should be available as cows exit the milking parlor and placed within 50 feet $(15 \mathrm{~m})$ of the feed bunk in housing pens. Tanks should be at least 3 feet long and 2 feet wide $(91 \mathrm{~cm} \mathrm{x} 61 \mathrm{~cm})$ for every 20 cows in a group. Each cow should have a trough space of 3.5 linear inches $(9$ linear $\mathrm{cm}$ ) in order to consume adequate amounts of water. 
Insufficient intake leads to immediate reduction in feed intake and subsequent milk production.

When it comes to feeding, cows have a natural aggressive behavior. When grouping cows, it is important to understand that some competition at the feed bunk will occur even when unlimited access to feed is provided. Proper grouping of cows can result in decreased competition at the feed bunk, increased dry matter intake, and subsequent improvements in production. Cows may be grouped by parity (i.e., primiparous or multiparous), stage of lactation, and milk yield.

Grouping cows by parity should be a high priority because separating first lactation cows from older cows increases performance and farm profitability. Primiparous and multiparous cows have different behavior and space requirements. Usually, primiparous cows are less dominant and will often be pushed off of feed bunks, stalls, and water tanks by dominant cows (Grant and Albright 2001). When first lactation cows are housed separately, they experience increases in feeding time, meals per day, lying time, and subsequent milk production (Grant and Albright 2001).

The reasons to group cows by stage of lactation include the low dry matter intake of fresh cows and the over conditioning and low milk production of late lactation cows. A separate fresh cow group has many potential benefits. Even though fresh cows do not have nutrient requirements that differ from those of cows at other stages of lactation, fresh cows are more susceptible to metabolic problems and may have decreased feed intake. It is important to keep fresh cows in a smaller group where farm staff can monitor them. The number of days that cows stay in the fresh cow pen varies from three to 45 days. However, the minimum should be three weeks, which is the period when cows are more susceptible to diseases and have massive weight loss. Keeping fresh cows in a separate group during this period allows farm staff to monitor cow health and determine when the cows should be moved to a separate group. Stocking density, days in milk, milk yield, and health status are decision factors that should be considered when moving fresh cows to other groups.

Milk yield is the major factor affecting the diet specifications of dairy cows. When grouping mature cows by milk yield, it is important to consider nutritional requirements. Cows producing large amounts of milk may be in negative energy balance (i.e., mobilizing body fat), so it is important to ensure a balanced, nutrient-dense diet for them. Cows with low milk yield are usually at the end of their lactation and will soon be dried off. These cows are in positive energy balance, so it is important to provide them with a diet that can support milk production but prevent excessive body condition. In many dairy operations, grouping cows and feeding appropriate diets result in an economic advantage.

The dry period is another critical phase in a dairy cow's lactation cycle. During the dry period, cows are able to recover from the last lactation and prepare for the next one. Poor nutritional management during this period results in significantly reduced milk production during the subsequent lactation. Dry cows should be placed in two different groups according to nutritional requirements. The far-off group includes cows that have just been dried until about 21 days before the expected calving date (from 230 to 255 days of gestation). It is important to maintain adequate body condition score during this period. Excessive body condition score increases the risk of metabolic problems during the fresh period. Dry cows are moved to a close-up group at 21 days before the expected calving date until calving (256 days of gestation). During this period, there is usually a decrease in feed consumption. It is critical to formulate a diet to meet nutritional requirements and decrease the chances of metabolic diseases post-calving.

Besides grouping management, the main factors that stimulate feeding behavior in dairy cows are delivery of fresh feed, feed push-up, and milking (Grant and Miner 2015). The ideal feed management in a dairy operation consists of always having adequate quantities of high-quality feed available on demand ( 21 hours per day), diets preferentially fed as total mixed rations provided at least twice a day, bunk stocking density equal to or less than $100 \%$, and feed push-ups for 2 hours post-feeding (Grant and Miner 2015).

\section{Stocking Density}

Stocking density is another important factor that affects the daily time budget, productivity, and welfare of a dairy cow. Overstocking interferes with cows' ability to express their natural behaviors. Increased stocking density in free-stall facilities is associated with less time lying down, an increase in aggressive interactions among cows, and a decrease in feeding time, which may lead to decreased rumen health and feed efficiency (Fregonesi, Tucker, and Weary 2007). Bach et al. (2008) also documented negative effects of stocking density on milk production. Hill (2006) observed that increases in stocking density reduced milk fat percentage and increased somatic cell count. Stocking density may also negatively affect reproductive performance. Evaluation of data from 153 farms showed that a decrease in bunk space was associated with a decrease in percentage of cows pregnant by 150 days in milk from 70 to 35\% (Caraviello et 
al. 2006). In addition, reduced conception rates have been observed with higher stocking densities (Schefers et al. 2010).

Long-term overstocking may reduce farm profitability due to its effects on health, reproduction, and milk yield. Grant and Miner (2015) found that resting time decreases and additional decreases in performance may occur when stocking density is over $120 \%$ in free-stall facilities.

\section{Heat Stress and Cow Comfort}

Dairy cattle become susceptible to heat stress when the ambient temperature rises above the cow's upper critical temperature, which results in physiological changes to decrease heat load in the body. The negative effects of heat stress in dairy cattle performance are well-documented. Lactating cows exposed to heat stress have decreased feed intake, altered metabolism, reduced milk production, impaired reproductive performance, and increased incidence of diseases (Fuquay 1981; Kadzere et al. 2002; West 2003). Additionally, recent studies have shown that cows exposed to heat stress during the dry period have decreased milk production in the subsequent lactation (do Amaral et al. 2009; Tao et al. 2011; Tao et al. 2012). Furthermore, dry period heat stress is negatively associated with measures of immune status and reproductive performance in dairy cows (do Amaral et al. 2011; Thompson and Dahl 2012).

Measurement of both ambient temperature and relative humidity (i.e., temperature humidity index, or THI) is the method used to estimate exposure to heat stress in dairy cattle. However, when animals are housed in open lots and directly exposed to the sun, THI underestimates heat stress because it does not take into consideration the effects of solar radiation. Definitions of exposure to heat stress according to THI values vary among researchers. Armstrong (1994) described a THI below 71 as a thermal comfort zone for dairy cows, between 72 and 79 as mild heat stress, between 80 to 90 as moderate heat stress, and over 90 as severe heat stress. More recently, Collier et al. (2011) observed that high-producing cows began to be negatively affected by heat stress at a THI value as low as 68 .

According to Cook et al. (2007), as THI increased from 56 to 74 , lying time decreased from 10.9 to 7.9 hours per day, standing increased from 2.6 to 4.5 hours per day, and drinking increased from 0.3 to 0.5 hours per day. In addition, lameness increased due to greater periods of standing time. Tapki and Sahin (2006) documented that as air temperature increased from 78 to $104^{\circ} \mathrm{F}$, high-producing cows (more than 70 pounds per day) had decreases in feed intake of $46 \%$, decreases in rumination of $22 \%$, increases in standing of $34 \%$, increases in water intake of $30 \%$, and decreases in locomotion of $19 \%$. High-producing cows exhibit more signs of heat stress than low-producing cows because they generate more heat. In order to produce high amounts of milk, these cows eat more and produce more heat to metabolize feed nutrients.

Physiological signs of heat stress in dairy cows are increases in respiration rate, rectal temperature, water intake, sweating, and salivation. As THI increases, cows' respiration and sweating rates rise. Once those measures are overcome, panting and increased standing time occur in an attempt to maintain normal body temperature. It is important to understand the physiological changes caused by heat stress in order to implement effective cooling practices that minimize the negative effects of heat stress.

Such practices include providing dairy cows with an adequate quantity of drinking water, shade, and ventilation, and by using water sprinklers to help cows dissipate heat (evaporative cooling). Changes in feeding management can also be implemented in conditions of heat stress, because cow maintenance requirements increase while dry matter intake goes down under heat stress conditions. It is important to increase density of energy and other nutrients to compensate for the decrease in dry matter intake.

Clean and fresh drinking water must be available to cows at all times. During times of heat stress, cows dissipate heat through respiration and sweating, which increase water consumption by up to $50 \%$. If the water supply is inadequate in heat stress conditions, cows will divert the water normally used in milk synthesis to physiological processes involved in heat dissipation. Additional temporary water sources during heat stress conditions may be used in dairy facilities to minimize the negative effects of heat on dairy cattle. Providing maximum shade in housing areas and holding pens is another important measure for heat abatement. If cows are kept outside on pasture or a dry lot, it is important to provide temporary or permanent shade structures to reduce cow exposure to direct solar radiation. In addition, providing shade over the feeding area results in increased feed intake. Increasing airflow is another important component when trying to decrease the negative effects of heat stress in dairy cattle. Adequate barn ventilation is essential to facilitate cows' physiological cooling efforts. Ventilation decreases the effects of heat stress by providing air exchange between the inside and outside of the barn, which assists with the removal of excess heat and moisture. The main ways to increase airflow are by using fans and, depending on design, by opening the sides of the 
barn to allow maximum air flow. Low-pressure sprinklers and adequate airflow along feed bunks and holding areas are very effective. Sprinklers should be on a timer and cycle on and off at higher frequency as temperatures rise. After being soaked, cows are cooled by transferring heat to evaporate water if adequate fan capacity is present.

Long-term monitoring of cows and facilities allows for identification of opportunities to incorporate additional management and cooling strategies to alleviate heat stress. Preventing the negative effects of heat stress in dairy cows helps maximize cow comfort, production, health, and animal welfare in dairy operations.

\section{Conclusion}

Modern dairy facilities should enhance cow comfort to increase productivity and profitability. When designing facilities, keep in mind that the facility will affect the performance of cows for many years. Investment in cow comfort should be seen as a long-term benefit instead of an additional expense. Understanding cow behavior allows producers to determine what adjustments can be made to best fit the needs of cows in different types of facilities.

\section{References}

Armstrong, D. V. 1994. "Heat stress interactions with shade and cooling." J. Dairy Sci. 77: 2044-2050.

Bach, A., N. Valls, A. Sloans, and T. Torrent. 2008. "Associations between nondietary factors and dairy herd performance." Journal of Dairy Science 91: 3259-3267.

Calamari, L., F. Calegari, and L. Stefanini. 2009. "Effect of different free stall surfaces on behavioural, productive and metabolic parameters in dairy cows." Applied Animal Behavior Science 120: 9-17.

Beede, D. K. 2005. "Assessment of water quality and nutrition for dairy cattle." In Proceedings of the Mid South Ruminant Nutrition Conference. Arlington, TX.

Bray, D. R. 1998. “Cow comfort at the feeding area." In The Proceedings of the Dairy Feeding Systems Management, Components, and Nutrients Conference. NRAES 116. Natural Resource, Agriculture, and Engineering Service. Cornell University, Ithaca, NY.

Caraviello, D. Z., K. A. Weigel, P. M. Fricke, M. C. Wiltbank, M. J. Florent, N. B. Cook, K. V. Nordlund, N. R. Zwald, and C. L. Rawson. 2006. "Survey of management practices on reproductive performance of dairy cattle on large US commercial farms." Journal of Dairy Science 89: 4723-4735.

Collier, R. J., R. B. Zimbelman, R. P. Rhoads, M. L. Rhoads, and L. H. Baumgard. 2011. "A re-evaluation of the impact of temperature humidity index (THI) and black globe humidity index (BGHI) on milk production in high producing dairy cows." In Proceedings of the Western Dairy Management Conference. Reno, NV.

Cook, N. B., R. L. Mentink, T. B. Bennett, and K. Burgi. 2007. "The effect of heat stress and lameness on time budgets of lactating dairy cows." Journal of Dairy Science 90: 1674-1682.

Cooper, M. D., D. R. Arney, and C. J. C. Phillips. 2007. "Two- or four-hour lying deprivation on the behavior of lactating dairy cows." Journal of Dairy Science 90: 1149-1158.

do Amaral, B. C., E. E. Connor, S. Tao, M. J. Hayen, J. W. Bubolz, and G. E. Dahl. 2009. "Heat-stress abatement during the dry period: Does cooling improve transition into lactation?" Journal of Dairy Science 92: 5988-5999.

do Amaral, B. C., E. E. Connor, S. Tao, M. J. Hayen, J. W. Bubolz, and G. E. Dahl. 2011. "Heat stress abatement during the dry period influences metabolic gene expression and improves immune status in the transition period of dairy cows." Journal of Dairy Science 94: 86-96.

Espejo, L. A. and M. I. Endres. 2007. "Herd-level risk factors for lameness in high-producing Holstein cows housed in freestall barns." Journal of Dairy Science 90: 306-314.

Fregonesi, J. A., C. B. Tucker, and D. M. Weary. 2007. "Overstocking reduces lying time in dairy cows." Journal of Dairy Science 90: 3349-3354.

Fuquay, J. W. 1981. "Heat stress as it affects animal production." Journal of Dairy Science 52: 164-174.

Gomez, A. and N. B. Cook. 2010. "Time budgets of lactating dairy cattle in commercial freestall herds." Journal of Dairy Science 93: 5772-5781.

Grant, R. J. 2004. "Incorporating dairy cow behavior into management tools." In Proceedings Cornell Nutrition Conference for Feed Manufacturers, East Syracuse, NY. Cornell University, Ithaca, NY. 
Grant, R. J. and J. L. Albright. 2000. "Feeding behaviour.” In Farm Animal Metabolism and Nutrition, edited by J. P. F. D’Mello. New York, NY: CABI Publishing.

Grant, R. J. and J. L. Albright. 2001. "Effect of animal grouping on feeding behavior and intake of dairy cattle." Journal of Dairy Science 84(E Suppl.): E156-E163.

Graves, R., D. McFarland, J. Tyson, and T. Wilson. 2005. "Cow freestall (Cubicle) types and details. Dairy Idea Plan 821." Penn State Agricultural \& Biological Engineering Cooperative Extension. http://host31.spidergraphics.com/ nra/doc/fair\%20use\%20web\%20pdfs/nraes-200_web.pdf

Grant, R. J. and W. H. Miner. 2015. Economic Benefits of Improved Cow Comfort. St. Charles, MO: Novus Int.

Hill, C. T. 2006. The Effects of Stocking Rate, Parity, and Lameness on the Short-Term Behavior of Dairy Cattle. MS Thesis. University of Vermont, Burlington, VT.

Hopster, H., G. N. Hermans, B. Engel, and J. T. N. Van der Werf. 2002. "Behavioural and physiological consequences of deprivation from nightly lying in dairy cows." In Proceedings 36 International Congress International Society of Applied Ethology. Zan am Zee, The Netherlands.

Kadzere, C. T., M. R. Murphy, N. Silanikove, and E. Maltz. 2002. "Heat stress in lactating dairy cows: A review." Livestock Production Science 77: 59-91.

Matzke, W. C. 2003. Behavior of Large Groups of Lactating Dairy Cattle Housed in a Free Stall Barn. MS Thesis. University of Nebraska, Lincoln, NE.

Metz, J. H. M. 1985. "The reaction of cows to a short-term deprivation of lying." Applied Animal Behavior Science 13: 301-307.

Munksgaard, L., M. B. Jensen, L. J. Pederson, S. W. Hansen, and L. Matthews. 2005. "Quantifying behavioural priorities-Effects of time constraints on behaviour of dairy cows, Bos taurus." Applied Animal Behavior Science 92: 3-14.

Overton, M. W., W. M. Sischo, G. D. Temple, and D. A. Moore. 2002. "Using time-lapse video photography to assess dairy cattle lying behavior in a free-stall barn." Journal of Dairy Science 85: 2407-2413.

Reich, L. J., D. M. Weary, D. M. Veira, and M. A. G. von Keyserlingk. 2010. "Effects of sawdust bedding dry matter on lying behavior of dairy cows: A dose-dependent response." Journal of Dairy Science 93: 1561-1565.

Schefers, J. M., K. A. Weigel, C. L. Rawson, N. R. Zwald, and N. B. Cook. 2010. "Management practices associated with conception rate and service rate of lactating Holstein cows in large, commercial dairies." Journal of Dairy Science 93: 1459-1467.

Tao, S., J. W. Bubolz, B. C. do Amaral, I. M. Thompson, M. J. Hayen, S. E. Johnson, and G. E. Dahl. 2011. "Effect of heat stress during the dry period on mammary gland development." Journal of Dairy Science 94: 5976-5986.

Tao, S., I. M. Thompson, A. P. A. Monteiro, M. J. Hayen, L. J. Young, and G. E. Dahl. 2012. "Effect of cooling heat-stressed dairy cows during the dry period on insulin response." Journal of Dairy Science 95: 5035-5046.

Tapki, I. and A. Sahin. 2006. "Comparison of the thermoregulatory behaviours of low and high producing dairy cows in a hot environment." Applied Animal Behavior Science 99: 1-11.

Thompson, I. M. and G. E. Dahl. 2012. "Dry period seasonal effects on the subsequent lactation." Professional Animal Scientist 28: 628-631.

Tucker, C. B., D. M. Weary, M. A. G. von Keyserlingk, and K. A. Beauchemin. 2009. "Cow comfort in tie-stalls: Increased depth of shavings or straw bedding increases lying time." Journal of Dairy Science 92: 2684-2690.

Wagner-Storch, A. M., R. W. Palmer, and D. W. Kammel. 2003. "Factors affecting stall use for different freestall bases." Journal of Dairy Science 86: 2253-2266.

West, J. W. 2003. "Effects of heat-stress on production in dairy cattle." Journal of Dairy Science 86: 2131-2144. 
Table 2.

\begin{tabular}{|c|c|c|c|c|c|c|c|c|}
\hline & \multicolumn{2}{|c|}{ Total Stall Length (in) } & \multicolumn{2}{|c|}{ Length (in) } & Width (in) & \multicolumn{2}{|c|}{ Height (in) } \\
\hline $\begin{array}{c}\text { Animal Weight } \\
\text { (lb) }\end{array}$ & $\begin{array}{c}\text { Closed } \\
\text { Front }\end{array}$ & Open Front & $\begin{array}{c}\text { Brisket Tube } \\
\text { or Board }\end{array}$ & Neck Rail & $\begin{array}{c}\text { Center to } \\
\text { Center }\end{array}$ & $\begin{array}{c}\text { Top of } \\
\text { Partition }\end{array}$ & $\begin{array}{c}\text { Neck Rail } \\
\text { Brisket Tube } \\
\text { or Board }\end{array}$ \\
\hline $900-1,100$ & $90-96$ & $78-82$ & $64-66$ & $62-64$ & $41-43$ & $42-44$ & $42-44$ & $4-6$ \\
\hline $1,100-1,300$ & $96-102$ & $80-86$ & $66-68$ & $64-66$ & $43-45$ & $44-46$ & $44-46$ & $4-6$ \\
\hline $1,300-1,500$ & $102-108$ & $90-96$ & $68-70$ & $66-68$ & $45-48$ & $46-48$ & $46-48$ & $4-6$ \\
\hline $1,500-1,700$ & $108-114$ & $96-102$ & $70-72$ & $68-70$ & $48-52$ & $48-52$ & $48-52$ & $4-6$ \\
\hline
\end{tabular}

